Estudios Románicos, Volumen 29, 2020, pp. 147-163

ISSN: 0210-4911

eISSN: $1989-614 \mathrm{X}$

DOI: https://doi.org/10.6018/ER.402591

\title{
O GALEGO, UNHA LINGUA SEN DIALECTOS: OLLADAS SOCIAIS E LINGÜÍSTICAS SOBRE A VARIACIÓN DIALECTAL
}

(Galician, a language without dialects: social and linguistic views on dialectal variation)

Francisco Dubert-García*

Instituto da Lingua Galega - Universidade de Santiago de Compostela

\begin{abstract}
Galician dialectologists often deny that Galician language includes dialects and take this absence as an evidence of its unity. However, these scholars group the different geographical varieties into entities that they may refer to as blocks, areas or types. In this paper I will analyse the way Galician dialectologists stablish the unity of Galician language, organize its geolectal varieties and justify its autonomy with respect to its neighbour languages. My approach suggests that there exist two ways of looking at the Galician dialectal varieties: a social and a linguistic view.
\end{abstract}

Keywords: Galician; Portuguese; Asturian-Leonese; Dialectology; Romance dialectology.

Resumo: Os dialectólogos galegos adoitan negar que o galego conteña no seu seo dialectos e interpretan esta ausencia como mostra da súa unidade. Con todo, estes investigadores agrupan as diversas falas en entidades que poden denominar bloques, áreas ou modalidades. Neste traballo analízase como os dialectólogos galegos establecen a unidade do galego, organizan as súas variedades xeolectais e xustifican a súa autonomía fronte ás linguas veciñas. A miña aproximación mostra que existen dúas formas de contemplar as falas galegas: unha ollada social e outra lingüística.

Palabras chave: Galego; Portugués, Ástur-leonés; Dialectoloxía; Dialectoloxía románica.

* Dirección para correspondencia: Francisco Dubert García. Facultade de Filoloxía, Avda. Castelao s/n, 15782 Santiago de Compostela (francisco.dubert@usc.es). 


\section{Introdución ${ }^{1}$}

Un tópico dos traballos de dialectoloxía galega é que o galego contén variación dialectal, pero non dialectos:

A unidade do galego vivo é moi grande, non hai fragmentación dialectal; así e todo, a combinación de moitos dos rasgos que agora imos tratar hanos permitir delimitar unhas cantas áreas lingüísticas, con rasgos de seu frente ás falas veciñas, áreas que non consideramos «dialectos», entre outras cousas porque os seus falantes non teñen conciencia de empregaren un galego «dialectal» (Fernández Rei 1985a: 486).

O caso do galego resulta en ocasións singular, sobre todo a termos en conta o seu percurso histórico afastado de universidades, liceos e academias: como idioma que é, a pesar de presentar, como todos, certa sorte de variacionismo xeográfico ou rexional, demostra ter unha notabilísima unidade, non se podendo afirmar que posúe dialectos internos [...]. Contrastivamente, o que con certeza podemos defender é a existencia de falas ou falares, distribuídos xeograficamente mais que non chegan a se constituír en dialectos (Sánchez Rei 2011: 168-169).

A inexistencia de dialectos en galego parece só unha cuestión terminolóxica. Segundo Carballo Calero (1979: 70), os conceptos de lingua e dialecto xorden da "abstracción de determinadas características naturales"; non son designacións "inequívocas de realidades concretas" e "significan lo que previamente se haya decidido que signifiquen, y tal decisión es convencional". Con todo, as definicións mostran que entidades se identifican no mundo, como se delimitan, que elementos constitutivos se consideran pertinentes e como se xerarquizan. Analizar como se establece se o galego ten ou non dialectos mostra como se (re)coñecen a lingua galega e as súas variedades. Por exemplo, négase a existencia de dialectos e relaciónase esta ausencia coa unidade da lingua.

Neste traballo analizarei como os dialectólogos galegos establecen a unidade do galego, organizan as súas variedades xeolectais e xustifican a súa autonomía fronte ás linguas veciñas. Nesta análise só presto atención ós traballos actuais; para visións anteriores, véxase Sánchez Rei (2011). Deste xeito, en §2 reflexiono sobre como perciben a variación dialectal os dialectólogos galegos; en $\$ 3$ establezo as formas en que estableceron a unidade do galego; en $\S 4$ analizo como as aplicaron á individuación do galego; en $\S 5$ defendo unha ollada social como a mellor vía para explicar a realidade da lingua; en $\S 6$ van unhas breves conclusións.

1 Traballo realizado coa axuda ED431C 2017134 (Xunta de Galicia / FEDER) dentro do proxecto PGC2018-095077-B-C44 (Ministerio de Ciencia, Investigación y Universidades). Agradezo a Xulio Sousa e ós dous avaliadores anónimos os comentarios con que me axudaron a mellorar este traballo. 
O galego, unha lingua sen dialectos: Olladas sociais e lingüísticas sobre a variación dialectal

\section{A percepción da variación xeolingüística}

A negación da existencia de dialectos no galego parece remontar a García de Diego (1909: 155): "las diferencias que ofrece el gallego en sus diversas regiones no son tan profundas para poder constituir grupos dialectales" (tamén en García de Diego 1959: 129). Xa que non profunda máis, parece que as bases desta afirmación son as propias diferenzas dialectais entre as falas, isto é, factores lingüísticos e non socioculturais.

Esta idea resulta atractiva: segundo Hermida (1992: 194), desde o século XIX, "enraizara a crenza de que o galego estaba moi fragmentado dialectalmente e que en moitas ocasións non era posible a intercomprensión entre falantes de distintas provincias". Esta crenza servía para negar posibilidades á promoción do galego, percibido como un idioma incapaz "de satisfacer tódalas necesidades que debe cubrir unha lingua moderna e de cultura" (González Seoane 1991: 55). De feito, a fragmentación dialectal segue a ser usada para negar o status de lingua ó asturiano ou para cuestionar a súa estandarización (Andrés 2002: 121). Por iso resulta interesante que un lingüista non galego do prestixio de García de Diego xulgue que as diferenzas dialectais do galego non abondan para crear grupos dialectais: se o galego non está tan fragmentado, pódese someter a normas e converterse en lingua de cultura.

De feito, a unidade do galego é unha preocupación constante nestes textos. Así, Álvarez, Fernández Rei, Xove (1980: 235) indican que as isoglosas individuais "raramente coinciden, más bien se entrecruzan y dan la sensación de que el gallego no es más que un complicado sistema de hablas. No obstante, la unidad del gallego hablado es muy grande" (tamén Fernández Rei 1985b: 90). Estas afirmacións son paradoxais: dun lado, isoglosas individuais que rara vez coinciden e producen a sensación dun complicado sistema de falas; doutro, unha unidade grande (Carballo Calero 1979: 78 mesmo fala de uniformidade). Como pode ser grande a unidade do galego se as isoglosas dan sensación de diversidade? Engánannos os sentidos? De que depende a unidade? Da cantidade de isoglosas, da súa dispersión e entrecruzamento, ou de que non formen feixes?

Sábese que as falas situadas ó noroeste do Douro son constitutivas (Gargallo Gil 1995, Penny 2007, Santamarina 1994, Veny 1982), pois empréganse nos seus territorios desde a romanización, ó revés do que acontece cos falas substitutivas ou consecutivas do centro e do sur, substitutas do mozárabe previo: "por iso as falas aquí no norte son moito máis abundantes en fenómenos e as fronteiras entre elas son graduais non bruscas" (Santamarina 1994: 249).

Polo tanto, as diferenzas dialectais son cuantitativamente maiores no terzo norte da Península ca no resto, onde a nivelación as reduciu (Penny 2000). De feito, o mapa de isoglosas cuantitativas que elaborou Goebl (2013: 151) con datos fonéticos do ALPI parece mostrar que os valores das diferenzas interpuntuais son altos no noroeste da Península. Se é así, nesta rexión a variación xeolingüística é grande. Ora ben, desde un punto de vista cuantitativo, cabe preguntar: cantas variables dialectais ou cantas variantes por variable dialectal permiten aínda falar de unidade? E desde un punto de vista cualitativo, cabe preguntar: que tipo de diferenzas entre as variantes dunha varia- 
ble dialectal permiten falar de unidade?, conta máis a variación nos verbos irregulares ou nos regulares?, conta máis o seseo, a gheada ou os resultados de -ANUM? E, sobre todo, por que?

Deste xeito, tras revisar a proposta de clasificación das falas galegas de Francisco Fernández Rei (1990), Rodríguez Alonso (1992: 68) xulga que esta sistematización, "a pesar de su inicial afirmación sobre la unidad del gallego, nos da la sensación de una lengua excesivamente fragmentada". Ora ben, Rodríguez Alonso non se refire ás isoglosas en bruto, previas á súa xerarquización en áreas e bloques, senón a unha clasificación que xa é unha abstracción e que simplifica a realidade dialectal. De certo, a contemplación das isoglosas en bruto provocaría en Rodríguez Alonso unha maior sensación de falta de unidade. Para evitar a sensación da excesiva fragmentación, Rodríguez Alonso propón que o mapa dialectal galego se reduza a dúas áreas (coma as de Zamora Vicente 1953), unha atlántica e outra continental. Como a fronteira entre os fenómenos dialectais non é ríxida, estas dúas variedades "no quiebran el sentido de unidad que de su lengua tiene el hablante gallego". Pero: de onde sae este sentido de unidade?

\section{Como se establece a unidade do galego?}

Constatada a diversidade interna do galego e as dificultades á hora de valorala en cantidade e calidade, como se logra establecer a unidade do galego? Desde o meu punto de vista, os investigadores galegos seguen dous camiños: a ollada lingüistica, baseada en feitos lingüísticos; e a ollada social, baseada nas crenzas dos falantes.

\subsection{A ollada lingǘstica: a intelixibilidade mutua}

Carballo Calero (1978) atribúe a unidade do galego e a inexistencia de dialectos no seu seo á falta de diverxencias lingüísticas internas de entidade. A demostración da falta de entidade das diverxencias está para el na intelixibilidade mutua:

Non existirían dialectos, senón falares dentro do galego. Ésta ven ser a opinión de Vicente García de Diego (1909), e é unha opinión correcta se o noso concepto de dialecto se basea na existencia de sustantividades diverxentes que entrañen a imposibilidade ou a dificultade de intercomunicación. [...] Hai diferencias de léxico e de realizacións fonemáticas, de entoación e de morfoloxía que non afectan á mutua comprensión. O galego non é, pois, un conxunto de dialectos ao xeito do retorrománico, por exemplo, que presenta importantes sumas de diverxencias antre os elementos constitutivos do seu grupo. Non hai dialectos dentro do galego moderno ao xeito que os hai dentro do actual complexo occitánico, co seu gascón e o seu provenzal afastados por nidias diverxencias (Carballo Calero 1978: 348).

Hai variación, pero non dialectos, pois as falas galegas son intelixibles. Carballo Calero (1978: 348-349) mostra que esta proposta deriva da definición de dialecto que manexa, baseada na intelixibilidade; con outras definicións poderíase falar de dialectos. 
Ora ben, a intelixibilidade tense usado para establecer se dúas variedades lingüísticas pertencen a unha mesma lingua, i.e., se se clasifican como dialectos dunha mesma lingua (Chambers, Trudgill 1998; Hudson 1996; Hockett 1958). Polo tanto, a intelixibilidade mostraría a unidade da lingua, non a inexistencia de dialectos, pois os falantes dos dialectos dunha lingua deberían poder entenderse. Porén, xa sabemos que existen dialectos intelixibles adscritos a linguas diferentes; e dialectos inintelixibles adscritos a unha lingua.

\subsection{A ollada social: a percepción dos falantes}

Outros autores usan outra xustificación totalmente diferente:

La combinación de muchos de estos fenómenos lingüísticos permite delimitar áreas [...], áreas con rasgos propios, frente a hablas vecinas, pero que en ningún momento consideramos dialectos, entre otros motivos porque sus hablantes no aprecian las diferencias lingüísticas como profundas y definitorias, porque no tienen conciencia de estar utilizando un "dialecto" del gallego (Fernández Rei 1985b: 91).

Véxase tamén Álvarez, Fernández Rei, Xove (1980: 235), Fernández Rei (1985a: 486; 1990: 35) e Sánchez Rei (2011: 168-169). Fernández Rei (1985b: 87) sostén que a definición de dialecto de Coseriu (1981), unha variedade xeolingüística subordinada a unha lingua histórica, non se pode aplicar ó galego, unha lingua "sen normalizar y todavía en un período constituyente de normativización”. Fernández Rei non xustifica esta afirmación. Porén, non se entende por que unha lingua sen normativizar non pode ter dialectos. Polo tanto, que entenden por dialecto Fernández Rei e Sánchez Rei nestes treitos e como negan a existencia de dialectos en galego? Parten, como vemos, da consciencia dos falantes, unha visión que vou denominar unha ollada social. Dubert García (2004), seguindo a Harris (1988, 1989), sostén que os dialectos de ollada social son entidades da mesma natureza cás linguas históricas de Coseriu: un dialecto de ollada social é unha entidade sociocultural, emic, resultado de como os falantes categorizan a realidade lingüística.

De feito, cando os membros dunha comunidade nomean o xeito en que falan crean unha entidade lingüística emic que podemos clasificar como socio-histórica; moitas veces, non sempre, o nome coincide co da comunidade ou do grupo étnico a que pertencen os falantes (Varvaro 2013). Este feito indica o carácter socio-histórico do fenómeno de identificación, pois os grupos étnicos son tamén entidades cuxos membros "son conscientes de su existencia como grupo separado del resto de la población" (Harris 1988: 527). É claro que os galegos forman un grupo étnico, unha nación-cultura (Villares 2017), fronte a asturianos, portugueses ou andaluces, e que, a pesar das súas innumerables diferenzas internas, se contemplan a si mesmos como un grupo. Quizais estea aí a razón de que os galegos non distingan dialectos de ollada social dentro de galego. 
Do mesmo modo, xulga Dubert García (2011) que as entidades lingüísticas sociohistóricas, linguas ou dialectos, constitúen o que Searle denomina feitos institucionais, "hechos objetivos en el mundo, que son hechos sólo merced al acuerdo humano" (1995: 21). De feito, Searle afirma que son entidades epistemicamente obxectivas, coñecemento da realidade compartido (diferentes das entidades ontoloxicamente obxectivas, coma as pedras ou os animais; 1995: 27-28). Os referentes das frases coma o galego, o portugués, o castelán, o castúo ou o andaluz son entidades reais por convención, porque os falantes as consideran reais e existentes; forman parte da súa realidade cultural e social, coma os cartos, o matrimonio, a relixión (véxase tamén Harris 1989: 49-56).

Pola contra, os bloques e áreas de Fernández Rei ou as modalidades de Carballo Calero son entidades etic, creadas polos lingüistas a partir dunha ollada lingüística. Para Fernández Rei, un bloque é un espazo xeográfico ocupado por variedades lingüísticas que partillan uns trazos lingüísticos; para Carballo Calero, unha modalidade é un grupo de falas que partillan varios trazos cuxa copresenza permite distinguila doutras modalidades. Así, bloques, áreas, modalidades son froitos da análise científica da lingua.

Os lingüistas poden oscilar entre unha ollada lingüística e unha ollada social. Por exemplo, Santamarina (1982) critica a Carballo Calero $(1969,1978)$ por usar a consciencia dos falantes. Para Santamarina (1982), Carballo Calero apela "ó sentimento lingüístico dos falantes, combinando deste xeito o método positivista da gramática comparativa co procedemento idealista da Einfühlung, que pode dar resultados válidos na crítica literaria pero nulos en dialectoloxía" (1982: 168-169)². Fernández Rei establece que a lingua galega carece de dialectos baseándose no mesmo procedemento idealista.

\subsection{O valor dos trazos lingüísticos na ollada social}

Ora ben, isto non significa esquecer que as olladas sociais se constrúen sobre feitos lingüísticos, pois non se conforman sobre a nada... Os falantes precisan encontrar trazos para delimitar entidades lingüísticas e clasificar un enunciado nunha lingua (Guy 2013: 64). Porén, os trazos usados polos lingüistas nas análises etic non sempre coinciden cos usados polos falantes nas análises emic. Os lingüistas poden soster que o galego se caracteriza por conter catro vogais medias distintivas... Non obstante, é un feito que moitos galegofalantes fundiron as vogais medias en cada localización. Ó oírmolos falar, dicimos que falan galego, aínda que lle acheguemos algún adxectivo (o novo galego urbano; Vidal Figueiroa 1997). De feito, toda a comunidade considera galegos estes textos. Todo isto significa que estas persoas efectivamente falan galego e que falar galego non implica necesariamente distinguir /e/ de / $/$, nin /o/ de / $/$.

Tras analizar como se estableceu a unidade do galego e a ausencia de dialectos, vou revisar como se empregaron estas dúas olladas para delimitar o galego.

2 Co tempo, Santamarina cambiou de opinión: "Quen vaia estrictamente con criterios de dialectólogo, segundo o fenómeno que escolla, encontrará facilmente argumentos para dicir que o bable ou asturiano chega á raia e que aínda pasa aló do Navia tantas ou cantas leguas. Pero as comunidades lingüísticas non se clasifican polo que din os libros de lingüística senón principalmente polas crenzas e sentimentos compartidos dos propios falantes" (Santamarina 1994: 249). 


\section{A identidade lingüística do galego entre as dúas olladas}

Segundo Andrés (2002, 2010), existen tres nocións enguedelladas no termo lingua: un sistema lingüístico, i.e., as unidades lingüísticas e os esquemas en que se combinan; unha unidade de clasificación glotolóxica que xorde da ollada lingüística; e unha entidade sociolóxica obtida pola ollada social. Na lingüística galega, a propia existencia da lingua histórica galega, a súa identidade e individuación, parecen asentar nun cruzamento entre unha ollada lingüística e outra social. Vexamos agora por que.

\subsection{A fronteira co ástur-leonés}

Aínda que os estudosos galegos insisten nas dificultades de trazar unha fronteira nítida entre galego e asturiano, acaban por concluír que a fronteira existe:

Malia a que hai isoglosas caracterizadoras (pero non exclusivas) do galego que chegan ata moito máis alá da vila asturiana de Lluarca (os ditongos decrecrentes en cousa, pouco, corredoira, vaqueiro, primeiro...) e, reciprocamente, algunhas isoglosas caracterizadoras do asturiano penetran máis acá do río Navia (o mantemento do -L- en palo, calente, molin, avola), existe unha fronteira máis ou menos definida na que coinciden moitos elementos que permiten diferenciar o territorio dunha lingua do territorio da outra, unha fronteira na que coinciden elementos capitais, e non só secundarios, na identificación dunha lingua fronte a outra (Costas González 2007: $49)^{3}$.

Fragmentos semellantes aparecen en Álvarez (2010: 89) ou Fernández Rei (1990: 18). Pode existir disparidade nos trazos usados ó trazar a fronteira galaico-asturiana, pero a súa existencia non se discute: como é sabido, establécea Ménendez Pidal (1906) coa isoglosa de (a)ditongación de Ě e ŏ tónicos latinos ${ }^{4}$. É, polo tanto, unha fronteira de ollada lingüística etic. Fernández Rei (1990), Seco Orosa (2001) ou Costas González (2007) repasan os trazos. Álvarez (2010), por exemplo, sitúa a fronteira na rexión pola que circulan as isoglosas eulyeu you do pronome da $1 \mathrm{sg}$, das formas meulmieu miou do posesivo masculino (que representan resultados de ě e ŏ) e da preservación/caída de

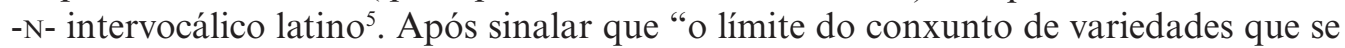
agrupan baixo unha mesma lingua histórica pode ser convencional para os lingüistas, [...] nunca o é para os falantes", asegura que "neste caso, a percepción deles coincide

3 Como dixen arriba, sería preciso saber que trazos son capitais, cales secundarios e, sobre todo, por que.

4 "A pesar de que la frontera del dialecto leonés con el gallego-portugués es bien precisa (á diferencia de la frontera oriental), está poco estudiada y mal conocida; es preciso ir marcando una línea que pase por entre pueblos vecinos, de los cuales los de Occidente no diptonguen la Ě e ŏ latinas, diciendo: corpo terra y los de Oriente las diptonguen: cuerpo tierra" (Méndez Pidal 1906: 130).

5 A estes trazos engade outros problemáticos: a palatalización /t $\mathrm{j} /$ do sufixo da 2sg do Pretérito Perfecto, pois hai dialectos galegos occidentais e sur-orientais sen esta palatalización; o sufixo /N/ da 1sg do Pretérito Perfecto, comín, pois hai outros dialectos galegos sur-orientais sen ese sufixo; a oposición telche en vinte pero deiche cartos, pois hai dialectos sur-occidentais e sur-orientais sen che dativo de OI. 
co límite trazado polos dialectólogos" (Álvarez 2010: 91), dando así a entender que a fronteira de ollada lingüística coincide coa de ollada social. Con todo, xa Santamarina (1994: 249-250) non ve claro que os asturianos do Eo-Navia consideren que falen galego. De feito, Llera Ramo e San Martín Antuña (2003) realizaron 300 entrevistas na zona; nelas preguntaron sobre "la denominación del habla de su área". Segundo os seus datos, o $33 \%$ dos enquisados chamoulle fala á súa variedade lingüística; o 24,7\%, gallego-asturiano; o $21,4 \%$, asturiano ou bable; o 5,3\%, chaporreo; e o $2 \%$, gallego. Para estes autores:

Quienes, por otro lado, utilizan las denominaciones de «fala» o «gallegoasturiano» podrían querer señalar, por una parte, la diferenciación de la lengua vernácula de su zona respecto a la del resto de Asturias y, por otra, la unidad de los registros vernáculos del Navia-Eo. Tan sólo uno de cada diez entrevistados $(11,4 \%)$ se decanta por las denominaciones localistas («fala d'A Veiga», «tapiego», etc.). Pero un hecho que llama la atención es la dificultad con que parece estar asentándose la denominación oficial de «gallego-asturiano», utilizada habitualmente por las instituciones asturianas, que aún no ha superado la popularidad de la denominación más tradicional de «fala», y apenas supera a la denominación «bable o asturiano», pese a que esta última rara vez es utilizada oficial y mediáticamente para referirse al habla del Navia-Eo (Llera Ramo, San Martín Antuña 2003: 87-88).

Se é así, parece que a maioría dos asturianos do Eo-Navia perciben que falan unha variedade distinta da do resto dos asturianos, e as fronteiras emic e etic coinciden polo leste; non se ve tan claro que consideren que falen galego e parecen situar unha fronteira emic con este polo seu oeste. Polo tanto, a inclusión do galego-asturiano no galego e a propia separación do asturiano do galego xorden da ollada lingüística, como mostra Andrés:

Existe un consenso xeneralizado na lingüística hispánica e románica segundo o cal a fronteira entre o asturiano e o galego discorre ó longo dunha linia NorteSul que máis ou menos corresponde á cunca do río Navia en Asturias. Así pois, na franxa máis occidental de Asturias, entre os ríos Navia e Eo (este na fronteira política) usaríanse falas de tipo galego. É decir: en Asturias non só existiría unha lingua autóctona de tipo asturiano-leonés, senón tamén unha lingua autóctona de tipo galego-portugués nos dezasete concellos da franxa máis occidental (Andrés 2010: 82).

O mesmo opina Santamarina (1994: 250), quen tras sinalar as actitudes ambiguas dos habitantes do oeste de Asturias con respecto a se falan galego ou outra cousa, afirma que "os dialectólogos neogramáticos, antes da invención da MDGA [Mesa para Defensa del Galego de Asturias, FDG], no seu afán de clasificaren idiomas e dialectos decidiran que o límite do galego era o da non ditongación de O, E breves". Segundo Santamarina: 
Cando se usa a expresión de galego-asturiano ou astur-galego non debemos entendelo como o substituto do tabú senón como unha denominación estrictamente xeográfica como cando dicimos galego fisterrán ou galego valdeorrano; porque non hai dous galegos, un de Galicia e outro de Asturias senón un galego só (Santamarina 1994: 250).

Ora ben, aínda que a fala do Eo-Navia é galego desde unha ollada lingüística, moitos dos seus falantes tratan desde unha ollada social esta variedade como algo distinto... En definitiva, moitos dos asturianos de fala galega teñen consciencia de falar algo distinto.

\subsection{A fronteira co portugués}

Os estudosos das falas galegas, porén, relacionan a separación de galego e portugués máis co sentimento dos falantes ca con factores lingüísticos. Para Carballo Calero:

Se a historia política non nos impón a súa psedoumórfose na consideración do galego, podemos situar o problema a outro nivel, e, fundados nas estructuras idiomáticas e non nas estruturas xurídicas, entender o galego no seu conxunto como unha modalidade do romance hispánico occidental, denominación que pode competir coa de galego-portugués, portugués ou galego — que todas foron propostas ou usadas - para designar o romance finistérrico ou extremo-occidental (Carballo Calero 1978: 352).

Véxase tamén Carballo Calero (1969: 3; 1978: 348). Pola súa parte, Cintra afástase da tradición dialectal portuguesa "ao considerar o território linguístico galego-português no seu conjunto, isto é, ao não isolar a Galiza do território politicamente português que a continua geográfica e linguisticamente para o Sul” (1971: 99). A razón de agrupar galego e portugués é lingüística: a falta de ditongación de ě e ŏ tónicos; sostén que os portugueses distinguen polo seu falar un galego e comprenden o seu dialecto, mais nel "não vêem normalmente, a não ser que tenham certa cultura histórica ou linguística, uma variedade do português, apenas porque a consciência da separação política os impede de sentir «linguisticamente» da forma que seria a mais normal" (1971: 101). Sobre como os dialectólogos portugueses trataron o galego, véxase Álvarez Pérez (2013).

Fernández Rei tamén considera que, desde unha ollada lingüística, galego e portugués son unha lingua:

$\mathrm{Na}$ actualidade, desde o punto de vista estrictamente lingüístico, ás dúas marxes do Miño fálase o mesmo idioma, pois os dialectos miñotos e trasmontanos son unha continuación dos falares galegos, cos que comparten trazos comúns que os diferencian dos do centro e sur de Portugal; pero no plano da lingua común, e desde 
unha perspectiva sociolingüística, hai no actual occidente peninsular dúas linguas modernas, con diferencias fonéticas, morfosintácticas e léxicas, que poden non impedi-la intercomprensión ó existir un bilingüismo inherente entre o galego e o portugués (Fernández Rei 1990: 17-18).

Para el, o galego non é lingüisticamente diferente "do portugués, porque entre estes dous «dialectos» latinos non hai unha forte separación lingüística, pero si a hai sociolingüística e socioliteraria” (1990: 18). Noutro lugar conclúe que:

Partindo de criterios extralingüísticos, como pode se-la conciencia xeral de falarmos un idioma que non é castelán nin portugués, aínda que próximo a este último (e proba desa conciencia é a loita por normalizalo, o esforzo constante por convertilo en lingua de cultura...) e tendo en conta a realidade lingüística do occidente peninsular, cremos que hoxe pode falarse da existencia de dous idiomas diferentes, galego e portugués (Fernández Rei 1982: 258).

Polo tanto, galego e portugués son dúas linguas distintas desde a ollada social, emic. De feito, a sociolingüística galega ofreceu unha descrición etic do proceso emic de constitución do galego como lingua histórica. Para iso empregou as nocións de lingua por elaboración e lingua por distanciamento (Fernández Rei 1996; Fernández Salgado, Monteagudo 1995). No noroeste da Península Ibérica xerouse unha lingua por distanciamento lingüístico, o galego-portugués, da que se xebraron por motivos socio-históricos dúas linguas por elaboración, o galego e o portugués. Esta separación socio-histórica repercutiu en ámbalas linguas, pois "o galego evoluciona e estende as súas innovacións dentro do seu espazo, sen ultrapasar xa nunca máis o seu límite cara ao sur; o mesmo fan as variedades portuguesas, pois as innovacións meridionais nunca chegan a cruzar o Miño cara ao norte" (Álvarez 2018: 77) ${ }^{6}$. A separación do galego e ástur-leonés, porén, nunca precisou de tales estudos sociolingüísticos e o apelo á consciencia dos falantes non se usa para trazar a fronteira entre galego e asturiano.

Polo tanto, está en cuestión se as isoglosas que separan galego e portugués, e que xeralmente coinciden coa fronteira política, posúen entidade lingüística suficiente para xebrar dúas linguas. Outra vez, cabe preguntarse: ten os mesmos poderes a eliminación das consoantes fricativas coronais voceadas cá falta de ditongación de Ĕ e ŏ?, como se ditamina esta importancia por medios estritamente lingüísticos?

\footnotetext{
6 Con todo, hai innovacións compartidas arriba e abaixo da fronteira, como por exemplo a xeración de consoantes nasais palatais a partir de [ĩ] en hiato (camĩo > camiño) ou a perda de nasalidade en hiatos coma os de cadealcadeia, coello/coelho etc. Nos dialectos do suroeste galego, o hiato ['כa] de palabras coma avoa ou moa contraeu en ['כ] do mesmo xeito que se fixo en portugués; tamén aparecen alí as variantes isto, iso, aquilo do chamado demostrativo neutro. Tamén existen evolucións polixenéticas compartidas en variantes coma andandes, cantabandes, cantais, colleis ou partín/partim etc. Elisa Fernández Rei 2019 mostra formas de continuidade na entoación entre as falas galegas e as portuguesas; non sabemos da antigüidade destes trazos.
} 
O galego, unha lingua sen dialectos: Olladas sociais e lingüísticas sobre a variación dialectal

\section{As entidades lingüísticas etic e a realidade social dos falantes}

Para Andrés (2010), non se deben mesturar as visións etic e emic, e cómpre establecer por medio de recursos estritamente lingüísticos as fronteiras entre as linguas. Con respecto ás opinións dos falantes, Andrés asevera que:

Agora ben, é unha obviedade recordar que a opinión dos falantes — que é digna do maior respecto - non constitúe ciencia lingüística; a opinión dos falantes non é suxeito de ciencia, senón obxecto de estudio pola parte de ciencias como a socioloxía. Os falantes saben falar, pero iso non lles outorga un coñecemento científico da súa propia fala. O que o lingüista determina polos sous [sic, FDG] propios medios glotolóxicos, non ten porqué coincidir coas opinións dos falantes; e viceversa (Andrés 2010: 82).

Con todo, bloques, áreas, modalidades, entidades etic creadas coa ollada lingüística e delimitadas mediante a selección dunha serie limitada de isoglosas son elementos deseñados polos investigadores para ordenar a variación xeográfica; en realidade, o que existe obxectivamente é o contínuum xeolectal; tamén existen como feitos sociais epistemicamente obxectivos as linguas e dialectos emic. Estes feitos provocan tres ideas: a) as entidades etic non iluminan a Historia do galego; b) as entidades etic adoitan ser irrelevantes na actividade comunicativa dos falantes; e c) as entidades emic si son relevantes na actividade comunicativa dos falantes. Exploremos estas tres ideas.

\subsection{Entidades etic e Historia}

Para comezar, vemos que existen tantas segmentacións dialectais etic do galego coma autores: Zamora Vicente (1953), Cintra (1971), Carballo Calero (1969, 1978), Fernández Rei (1982, 1990), Rodríguez Alonso (1992) e Frías Conde (1997). Todas estas unidades van de norte a sur (pois ese é precisamente un trazado común en moitas isoglosas da Iberorromania occidental constitutiva) e resultan de que o investigador prima unhas isoglosas e secundariza outras; as diferentes propostas reflicten só as diferentes xerarquías de isoglosas. Unha vez establecidas estas entidades etic, os estudosos procuran explicar con fundamentos históricos ou xeográficos a orixe das entidades que eles delimitaron (Álvarez, Dubert García, Sousa 2006, por exemplo). Con todo, a día de hoxe non se coñece ningunha explicación extralingüística que dea conta da existencia destas entidades etic. Como ben nota Sánchez $\mathrm{Rei}^{7}$, estas entidades non coinciden con ningunha estrutura histórica ou xeográfica previa. A razón paréceme obvia: a existencia, por exemplo, dos tres bloques de Fernández Rei (1990) depende só de canto se

7 "Non existe, no noso caso, unha variedade o suficientemente distintiva de seu que se poida denominar como coruñesa, como ourensá ou como lucense, moito embora haxa algúns trazos que poidan caracterizar os varios falares da Coruña, os de Ourense ou os de Lugo. Obsérvase, pois, as máis relevantes subdivisións non son de orde provincial, mais, noutra ocasión, de carácter vertical (faixa occidental, central e oriental)" (Sánchez Rei 2011: 383). 
expandiron os fenómenos fonéticos asociados ás diferentes formas de formación do plural dos nomes agudos rematados en consoante nasal. E, como xa sabemos, cada fenómeno dialectal ten a súa historia (aquí temos varios fenómenos fonéticos dialectais diferentes). Estas isoglosas separan tres bloques internos no galego e galego de ástur-leonés; mais, que elementos históricos ou xeográficos comúns poden explicar a difusión desigual de fonéticos distintos localizados en diferentes momentos históricos? A caída do -N- intervocálico que separa galego de ástur-leonés é un fenómeno distinto da resolución dos hiatos nasais que producen os tres bloques galegos.

Creo que non ten sentido buscar na Historia o porqué da división do galego en tres bloques: os estudosos primaron unhas isoglosas coas que crearon uns bloques que superpuxeron ó contínuum. Estes bloques resultan da acción racional dos investigadores.

\subsection{Entidades etic e relevancia para as actividades comunicativas dos falantes}

Cómpre recordar agora que os trazos seleccionados para establecer bloques e áreas son un subconxunto dos trazos que os falantes intercambian no territorio ó longo da historia, que cada trazo ten unha extensión individual e que as isoglosas transformadas en fronteiras non impiden o intercambio doutros trazos considerados menos relevantes, i.e., nin impiden nin dificultan as actividades comunicativas dos falantes.

Así, o plural do nomes agudos rematados en -n (pantalóns, pantalós, pantalois) distingue tres bloques galegos ó mesmo tempo que separa galego de asturiano (pantalones). Ora ben: a variante uns penetra na zona de pantalós ( $A L G a$ II, mapas 68 e 219); en Verín, galego central, encontramos illas só de variantes tipo pantalóns e mañán (Taboada 1979); a gheada divide o bloque central do galego de arriba abaixo e tivo illas no galego oriental (Fernández Rei 1990: 173-177); as variables colleulcolliu e parteulpartiu fragmentan o galego occidental en tres áreas e o galego central en dúas (aparece asemade unha área de colliu nos Ancares, Fernández Rei 1990: 83-84); na variable llolllelo < lles+o, a variante llo aparece en todo o galego occidental e todo o sur do galego central e oriental (Fernández Rei 1990: 74 e 80); as variantes tendes/vindes ocupan o sur e occidente de Galicia, con independencia da segmentación en bloques ( $A L G a I$, mapas 378 e 407). Estas e outras variables cabalgan entre os tres bloques e demostran que os bloques non interfiren na extensión e movementos dos trazos. Isto é, os bloques parecen ser irrelevantes para as actividades comunicativas dos falantes por medio das cales estes intercambian trazos.

O mesmo sucede co galego e o asturiano, pois vemos trazos compartidos por estas linguas que aparecen a ámbolos lado da fronteira galaico-asturiana, sen que esta impida o fluxo e intercambio: as variantes tipo camín e chen, resultados de -ĩNUM e -ËNUM; a variante con palatalización de -LL-; a variante con simplificación de -NN-; a variante [t]] resultado de PL-, CL-; a preservación de /t/ como resultado dos grupos -LT-/-CT-; a variante con preservación dos ditongos ei e ou; as variantes do tipo faigo, fas, fai do verbo facer; as variantes do Presente de Subxuntivo tipo día do verbo dar; as variantes tipo fix-e fiz-como radicais do verbo facer; os radicais palatalizados tipo quixemos do verbo querer. Polo tanto, os trazos, e non as fronteiras etic, teñen relevancia comunicativa para os falantes: poden intercambialos, exportalos, importalos... 


\subsection{Entidades emic e relevancia para as actividades comunicativas dos falantes}

Pola contra, as entidades emic teñen para os falantes relevancia socio-histórica e lingüística. A consciencia de falar algo distinto explica o cultivo literario e político das variedades identificadas: así xurdiron linguas coma o castelán, o galego, o catalán etc. O xurdir desta consciencia vai unido a factores sociais, históricos e xeográficos (Varvaro 2011). Unha vez establecidas estas entidades emic é cando os lingüistas lles propoñen fronteiras etic para delimitalas: a ollada lingüística é posterior á social:

Where the boundary between two languages is clear to sociolinguists, it is clear to everybody else as well - for example, there is no doubt that the languages spoken on opposite sides of the English Channel are different, but you don't need to be sociolinguist to be sure of that. And where the boundary is unclear to ordinary people, it is equally unclear to sociolinguists (Hudson 1996: 36).

O lingüista debe explicar a existencia das linguas e dialectos emic, entidades epistemicamente obxectivas que forman parte da realidade socio-histórica dos falantes, que estes constrúen focalizando determinados fenómenos lingüísticos. Coñecer que opinan os falantes sobre os feitos lingüísticos é outro deber do lingüista, pois as crenzas dos falantes explican por que unhas linguas permanecen e outras desaparecen; do mesmo xeito, como os falantes clasifican os feitos lingüísticos determina a historia interna das linguas que os conteñen: un trazo lingüístico etiquetado como pertencente a unha lingua pode ser rexeitado polos falantes doutra en virtude da existencia de tabús ó préstamo.

As linguas, quizais todas as linguas, son obxectos epistémicos socialmente construídos; recoñecelo non resta dignidade científica á profesión do lingüista nin ó seu obxecto de estudo.

\section{Conclusións}

Os dialectólogos galegos adoitan negar que o galego estea fragmentado en dialectos. Esta falta de dialectos é mostra, ademais, da unidade desta lingua. Para xustificaren a ausencia de dialectos, botan man da consciencia dos falantes, que non se identifican como falantes dun dialecto en concreto, senón como falantes de galego en xeral. Con todo, os investigadores segmentan o galego en unidades dialectais que chaman bloques, áreas e modalidades. Como é isto posible? Neste traballo quixen mostrar que esta non é só unha cuestión terminolóxica. Para iso, reviso como manexan os estudosos galegos a variación dialectal do galego.

Como resultado desta revisión, conclúo que os estudosos galegos estableceron a fronteira entre galego e ástur-leonés e as fronteiras interiores do galego mediante a selección dunhas isoglosas, con independencia das crenzas dos falantes; a este método chameille ollada lingüistica. Pola contra, a fronteira entre galego e portugués foi establecida sobre a consciencia dos falantes, pois as isoglosas que xebran galego e portugués parecen carecer do poder delimitador atribuído ás isoglosas que xebran galego de 
ástur-leonés; a este método chameille ollada social. Polo tanto, acabei mostrando que os dialectólogos galegos usan as dúas olladas á hora de segmentar o contínuum xeolectal do noroeste da Península Ibérica: a ollada social, emic, baseada na consciencia dos falantes; e a ollada lingüística etic, baseada na análise científica dos fenómenos lingüísticos. As entidades xeolingüísticas delimitadas por estas dúas olladas non necesariamente coinciden.

Ó meu xuízo, o lingüista debe aceptar que o modo natural de existir das linguas e dos dialectos reside na ollada social, emic, pois unhas e outros son entidades epistemicamente obxectivas, que forman parte da realidade socio-histórica dos falantes, que as constrúen focalizando determinados fenómenos lingüísticos. Máis aínda, só estas entidades emic teñen relevancia para a acción comunicativa dos falantes. Atender ó que os falantes cren sobre os feitos lingüísticos ilumina a Historia da lingua. Non sucede o mesmo coas entidades etic (bloques, áreas, modalidades), creacións dos lingüistas que os falantes ignoran na súa acción comunicativa.

\section{BIBLIOGRAFÍA}

ALGa I = Instituto da Lingua Galega (1990): Atlas Lingüístico Galego. Vol. I: Morfoloxía verbal. A Coruña: Fundación Barrié de la Maza.

ALGa II = Instituto da Lingua Galega (1995): Atlas Lingüístico Galego. Vol. II: Morfoloxía non-verbal. A Coruña: Fundación Barrié de la Maza.

ÁLVAREZ, Rosario (2010): "O galego oriental: variación lingüística na área de contacto co dominio asturleonés", Larouco 5, 87-92.

(2018): "Galego e portugués. Afinidade e diverxencia", Ana Rita Carrilho et alii (orgs.), Ao encontro das línguas ibéricas. Covilhã: Universidade da Beira Interior, 51-80.

ÁlVAREZ, Rosario; DUBERT GARCÍA, Francisco; SOUSA, Xulio (eds.) (2006): Lingua e territorio. Santiago de Compostela: Instituto da Lingua Galega/ Consello da Cultura Galega.

ÁLVAREZ, Rosario; FERNÁNDEZ REI, Francisco; XOVE, Xosé (1980): “Galego”, en Gran Enciclopedia Galega 14, 222-255.

ÁlVAREZ PÉREZ, Xosé Afonso (2013): “A fronteira entre galego e portugués. A perspectiva portuguesa”, Eva Gugenberger; Henrique Monteagudo; Gabriel Rei-Doval (eds.), Contacto de linguas, hibridade, cambio: contextos, procesos e consecuencias. Santiago de Compostela: Consello da Cultura Galega, 97-136.

ANDRÉS, Ramón d' (2002): Juicios sobre la lengua asturiana. Uviéu: Ámbitu. (2010): "Os límites entre os dominios lingüísticos e o seu tratamento. O caso do asturiano e o galego", Larouco 5, 77-86.

CARBALlO CALERO, Ricardo (1969): "Sobre os dialectos do galego", Grial 23, $1-15$.

(1978): "Sobre dialectoloxía do galego", Grial 61, 348-353.

(1979): Gramática elemental del gallego común. Vigo: Galaxia. 
COSERIU, Eugenio (1981): "Los conceptos de «dialecto», «nivel» y «estilo de lengua» y el sentido propio de la dialectología”, Lingüística española actual III/1, 1-32.

CHAMBERS, J. K.; TRUDGILL, Peter (1998): Dialectology. Cambridge: Cambridge University Press.

CINTRA, Luis F. Lindley (1971): "Nova proposta de classificação dos dialectos galego-portugueses", Boletim de Filologia 22, 81-116.

COSTAS GONZÁlEZ, Xosé-Herinque (2007): A lingua galega no Eo-Navia, Bierzo Occidental, As Portelas, Calabor e o Val do Ellas: historia, breve caracterización e situación sociolingüística actual. A Coruña: Real Academia Galega.

DUBERT GARCÍA, Francisco (2004): "Variedades xeolingüísticas e cultivo da lingua: crítica dunha hipótese sobre as orixes da fragmentación diatópica do galego", Rosario Álvarez; Antón Santamarina (eds.), (Dis)cursos da escrita. Estudos de filoloxía galega ofrecidos en memoria de Fernando R. Tato Plaza. A Coruña: Instituto da Lingua Galega / Fundación Pedro Barrié de la Maza, 123-140. (2011): "Sobre linguas e fronteiras no noroeste da Península", Ramón de Andrés (Coord.), Ciencia, lengua y fronteras, Uviéu: Trabe, 427-442.

FERNÁNDEZ REI, Elisa (2019): "La entonación de las variedades ibéricas occidentales", Josefa Dorta (ed.), Investigación geoprosódica. Amper: análisis y retos. Madrid/Frankfurt: Iberoamericana/Vervuert, 25-46.

FERNÁNDEZ REI, Francisco (1982): "Bloques e áreas lingüísticas do galego moderno", Grial 77, 257-296.

(1985a): "Áreas lingüísticas do galego actual”, Aina Moll (ed.), Actes. XVIe Congrès Internacional de Lingüistica i Filologia Romàniques (Palma de Mallorca, 1980), Vol. 2, 485-498.

(1985b): "Variedades dialectales del gallego", Revista de Filología Románica, vol. III, 85-99.

(1990): Dialectoloxía da lingua galega. Vigo: Xerais.

FRÍAS CONDE, Xavier (1997): "Sobre os bloques dialectais do galego: unha nova proposta", Revista de Filología Románica 1(14), 241-256.

GARCÍA DE DIEGO, Vicente (1909): Elementos de gramática histórica gallega (fonética-morfología). Burgos: Hijos de Santiago Rodríguez.

(1959): Manual de dialectología española. Madrid: Ediciones Cultura Hispánica.

GARGALLO GIL, José Enrique (1995): "De fronteras lingüísticas peninsulares: paralelismos, afinidades, peculiaridades", Lletres asturianes 57, 23-40.

GOEBL, Hans (2013): "La dialectometrización del ALPI: Rápida presentación de los resultados", Actas del XXVIé Congreso Internacional de Lingüística y de Filología Románicas. Vol VI. 143-154. Berlin: de Gruyter.

GONZÁLEZ SEOANE, Ernesto (1991): "Ideas sobre a fragmentación dialectal do galego no século XIX”, Mercedes Brea; Francisco Fernández Rei (coords.,) Homenaxe ó profesor Constantino García. Tomo II. Santiago de Compostela: Universidade de Santiago de Compostela, 55-67. 
GUY, Gregory R. (2013): "The cognitive coherence of sociolects: How do speakers handle multiple sociolinguistic variables?", Journal of pragmatics 52, 63-71.

HARRIS, M. (1988): Culture, people, nature. An introduction to general anthropology. New York: Harper \& Row. Cito pola tradución española Introducción a la antropología genaral. Madrid: Alianza, 2000.

(1989): Theories of culture in postmodern times. Walnuk Creek: Altamira Press. Cito pola tradución española Teorías sobre la cultura en la era posmoderna, Barcelona: Crítica, 2000.

HERMIDA, Carme (1992): Os precursores da normalización. Defensa e reivindicación da lingua galega no Rexurdimento (1840-1891). Vigo: Xerais.

HOCKETT, Charles F. (1958): A course in modern linguistics. New York: MacMillan. HUDSON, R. A. (1996): Sociolinguistics. Cambridge: Cambridge University Press.

LLERA RAMO, Francisco José; SAN MARTÍN ANTUÑA, Pablo (2003): II estudio sociolingüístico de Asturias. Uviéu: Academia de la Llingua Asturiana.

MENÉNDEZ PIDAL, Ramón (1906): "El dialecto leonés", Revista de archivos y bibliotecas. Año X, 2-3.

PENNY, Ralph (2000): Variation and change in Spanish. Cambridge: Cambridge University Press. Cito pola tradución española Variación y cambio en español, Madrid: Gredos, 2004.

(2007): "Continuum dialectal y fronteras estatales. El caso del leonés medieval", Argutorio 18, 32-37.

RODRÍGUEZ ALONSO, Manuel (1992): "La dialectología gallega", Revista de lengua y literatura catalana, gallega y vasca 2, 63-72.

SÁNCHEZ REI, Xosé Manuel (2011): Lingua galega e variación dialectal. Ames: Laiovento.

SANTAMARINA, Antón (1982): "Dialectoloxía galega: historia e resultados", Dieter Kremer; Ramón Lorenzo (eds.), Coloquio de Tréveris, Santiago de Compostela: Xunta de Galicia, 153187.

(1994): "Proposta de programa de normalización lingüística para os concellos de Asturias de fala galega", Francisco Fernández Rei (ed.), Lingua e cultura galega de Asturias. Vigo: Xerais, 241-264.

SEARLE, John R. (1995): The construction of social reality. New York: The Free Pres. Cito pola tradución española La construcción de la realidad social. Barcelona: Paidós, 1997.

SECO OROSA, Ana (2001): "Determinación da fronteira lingüística entre o galego e o leonés nas provincias de León e Zamora", Revista de filoloxía románica 18, 73-102.

TABOADA, Manuel (1979): El habla del valle de Verín. Santiago de Compostela: Universidad de Santiago de Compostela.

VARVARO, Alberto (2013): "Latin and the making of the Romance languages", Matin Maiden; John Charles Smith; Adam Ledgeway (eds.), The Cambridge history of the Romance languages. Volume 2. Contextes. Cambridge: Cambridge University Press. 
VENY, Joan (1982): Els parlars catalans. Sintesi de dialectologia. Mallorca: Moll. VIDAL FIGUEIROA, Tiago (1997): "Estructuras fonéticas de tres dialectos de Vigo", Verba $24,313332$.

VILLARES, Ramón (2017): “Trazos históricos dunha «nación-cultura»”, Identidade e afectos patrios. Vigo: Galaxia, 25-92.

ZAMORA VICENTE, Alonso (1953): "De geografía dialectal: -ao, -an en gallego", Nueva revista de filología hispánica VII, 1/2, 73-80. Cito pola edición Estudios de dialectología hispánica, Santiago de Compostela: Universidade de Santiago de Compostela, 27-34.

\section{PERFIL ACADÉMICO Y PROFESIONAL}

Francisco Dubert-García é profesor do Departamento de Filoloxía Galega da Universidade de Santiago de Compostela, membro do Consello Científico do Instituto da Lingua Galega (do que foi secretario en dúas ocasións) e actual codirector da revista Verba. Anuario Galego de Filoloxía. Dedícase sobre todo ó estudo da morfoloxía flexiva e da fonoloxía do galego. Ten publicado traballos sobre dialectoloxía, dialectometría, gramática (diacrónica e sincrónica) e contacto lingüístico. Foi coordinador do grupo de investigación Filoloxía e Lingüística Galega (FILGA) da USC e da rede de investigación interuniversitaria e interdisciplinaria Tecnoloxía e Análise de Datos Lingüísticos (TECANDALI). Forma parte do equipo de investigación do Atlas Lingüístico Galego. Véxase http://webspersoais.usc.es/francisco.dubert.

Fecha de recepción: 18/11/2020

Fecha de aceptación: 09/03/2020 